\title{
Desafios e perspectivas da Corte Internacional de Justiça
}

Paolo Palchetti*

\section{INTRODUÇÃO}

$\mathrm{O}$ artigo $1^{\circ}$ do Estatuto da Corte Internacional de justiça e o artigo 92 da Carta das Nações Unidas definem a Corte Internacional de justiça como um "órgão judiciário principal" das Nações Unidas. Todos os Estados-Membros das Nações Unidas (hoje mais de 290 Estados) são automaticamente partes do Estatuto da Corte e aceitam, portanto, as regras de funcionamento desse órgão. Com base nessas regras, a Corte pode resolver com base no direito internacional as controvérsias submetidas pelos Estados (art. 38, parágrafo $\left.1^{\circ}\right)^{1}$ e dar parecer sobre questões jurídicas $\left(\right.$ art. 65) ${ }^{2}$. Todavia, não obstante o papel atribuído à Corte pela Carta das Nações Unidas, a centralidade da Corte entre os vários mecanismos de solução de controvérsias não está garantida. Como se sabe, a jurisdição da Corte funda-se no consenso dos Estados: uma controvérsia é levada diante da Corte somente se existe um acordo entre as partes em confiar a ela a decisão sobre o caso. Os Estados, em geral, são relutantes em fazê-lo. Os Estados não aceitam que um terceiro, ainda que de grande autoridade, decida questões que podem ser de relevante interesse nacional. Eles preferem manter o controle sobre a decisão do caso, recorrendo no mais das vezes a negociações ou outras formas não jurisdicionais.

Apesar da resistência geral dos Estados em utilizar a Corte internacional de justiça ou, mais genericamente, tribunais internacionais, para resolver as suas controvérsias, é possível dizer, todavia, que nunca como nas décadas a Corte encontrou um significativo sucesso diante dos Estados. Tal sucesso demonstrou-

\footnotetext{
* Professor catedrático de Direito Internacional na Università degli studi di Macerata (Itália). Doutor em Direito pela Università degli studi di Milano (Itália) e advogado na Corte Internacional de Justiça (casos: "Bósnia versus Sérvia e Montenegro, 2006-2010"; "Papeleras, Argentina versus Uruguai, 2006-2007”; “Djibuti versus França, 2006-2008”; “Imunidades Diplomáticas, Alemanha versus Itália, 2009-2012”). Indirizzo Professionale: Dipartimento di Giurisprudenza, via Crescimbeni 14,62100, Macerata (Itália); palchetti@unimc.it
} 
se não somente pelo número de causas anualmente pendentes na Corte, mas também pelo conteúdo das controvérsias sobre as quais a Corte atualmente tem sido chamada a pronunciar-se.

É a partir desse dado que é preciso se perguntar quais são os "desafios" futuros para a Corte. Eis como pretendo organizar a minha intervenção hoje. Uma primeira parte será dedicada a ilustrar as diversas "épocas" da Corte, para demonstrar que a fase atual é de relativo sucesso ${ }^{3}$. Em uma segunda parte, serão examinados os "desafios" que esperam a Corte. Dois são os pontos sobre os quais eu gostaria de me debruçar: a) a exigência de estender o acesso a novos Estados e a novos atores; b) a exigência de dotar-se de novos instrumentos para tornar mais eficaz a sua ação.

\section{AS "ÉPOCAS" DA CORTE}

A primeira "época" corresponde, aproximadamente, aos anos 19461965, os primeiros anos de atividade da Corte. Nessa fase, a Corte foi chamada a pronunciar-se sobre várias controvérsias que envolvem, sobretudo, países europeus e da América latina. São numerosos, ainda, os pareceres requeridos pelas Nações Unidas. Nessa fase, os pronunciamentos da Corte contribuem de maneira significativa para o desenvolvimento do direito internacional, através de decisões inovadoras no âmbito do direito dos tratados e do direito marítimo.

A segunda "época" está entre 1965 e 1980. Trata-se de um período de profunda crise para a Corte. São pouquíssimas as controvérsias levadas a ela pelos Estados e poucos os pareceres requeridos pelas Nações Unidas. As razões são essencialmente duas. Em primeiro lugar, vemos nesse período uma profunda transformação do direito internacional sob a pressão dos países saídos do processo de descolonização. Esse período de transformação não favorece o recurso a uma Corte que sobre tal direito funda as suas decisões. O segundo motivo é o fato que a Corte é vista pelos novos Estados que passam a fazer parte da comunidade internacional como um instrumento dos países ocidentais para impor o "seu" direito aos Estados formados recentemente.

Essa situação muda a partir dos anos oitenta ${ }^{4}$. Certamente, uma contribuição importante na direção de uma recuperação da confiança na Corte foi a sentença emanada em 1986 na controvérsia entre Nicarágua e Estados Unidos. Com essa sentença, a Corte verificou as violações ao direito internacional, e, em particular, à proibição do uso da força, cometidas pelos Estados Unidos contra a Nicarágua. Trata-se de uma sentença que terá um alto valor simbólico: a grande potência que é condenada pela sua conduta diante de um pequeno país da América central. O segundo dado que contribui para reforçar o papel da Corte é a atitude de confiança mostrada pelos países que pertenciam ao antigo bloco socialista: se antes tais países negavam a possibilidade de voltar-se para a Corte, 
depois da queda do muro de Berlim, os novos Estados mostram-se prontos a aceitar a competência da Corte.

Chegamos, assim, à fase mais recente, que vai da metade dos anos noventa até hoje. Trata-se de um período em que a Corte recebe um número de casos como nunca em sua história. Esses casos provêm de Estados que pertencem a todas as áreas geográficas do mundo. E não só, pois são causas que se referem a acontecimentos políticos bastante relevantes: o genocídio na Bósnia, a longa controvérsia territorial entre dois importantes países africanos como Camarões e Nigéria, a controvérsia entre Irã e Estados Unidos em tema de uso da força. Uma última e importante observação é que essas causas levam a Corte a pronunciar-se sobre uma variedade extremamente ampla de questões de direito internacional: das controvérsias em matéria ambiental à tutela dos direitos humanos, do uso da força nas relações internacionais ao problema das imunidades de que gozam o Estado e os seus órgãos. Em suma, podemos definir o nosso tempo como a "época feliz" da Corte.

\section{OS "DESAFIOS": NOVOS ESTADOS E NOVOS ATORES}

Quais desafios esperam a Corte hoje ${ }^{25}$ Antes de mais nada, a Corte deverá tentar manter alto o interesse dos Estados e, se possível, conquistar o interesse dos novos Estados. Apesar do otimismo que o período atual parece impor, alguns sinais preocupantes são visíveis no horizonte. Limito-me a assinalar um: em dezembro de 2012, em resposta a uma decisão que a opunha à Nicarágua e que foi asperamente criticada, a Colômbia decidiu denunciar o pacto de Bogotá. Trata-se de uma convenção extremamente importante porque graças a ela muitos Estados da América Latina aceitaram atribuir à Corte a competência para resolver as suas controvérsias. E é verdade que os Estados da América latina são os melhores "clientes" da Corte. Ora, seria verdadeiramente um dano enorme para a Corte se outros Estados decidissem seguir o exemplo da Colômbia e denunciassem o pacto de Bogotá. Assinalo, a propósito, que dentro de alguns meses a Corte deverá emanar a sua decisão sobre a delimitação da fronteira marítima entre Peru e Chile. É uma questão muito importante politicamente para ambos os Estados e a Corte, na sua decisão, deverá atentar para não descontentar demais um dos dois Estados.

Um instrumento que a Corte deverá tentar valorizar para favorecer o acesso dos Estados é aquele previsto pelo art. 36, parágrafo 2, do Estatuto. ${ }^{6}$ Refirome à declaração unilateral de aceitação da competência da Corte, um instrumento que permite acessar unilateralmente à Corte nas relações entre Estados que fizeram essa declaração. Atualmente, essa declaração foi feita por 69 Estados. Um número bastante elevado, mas que não compreende muitos Estados “importantes". Basta pensar que entre os membros do Conselho de segurança, somente o Reino Unido fez a declaração. Além disso, é preciso considerar que a maior parte dos Estados que fizeram a declaração freqüentemente providenciaram a limitação da 
competência da Corte através da adoção de numerosas reservas. Sobre esse ponto, a Corte poderia tentar aumentar os próprios poderes através de interpretações restritivas dessas reservas.

Enfim, um meio para aumentar a utilização da Corte é permitir o acesso às organizações internacionais ${ }^{7}$. Atualmente, o Estatuto da Corte não permite que as organizações possam submeter controvérsias. Trata-se de um limite anacrônico que deveria ser removido. Para fazê-lo, é preciso modificar o Estatuto. É um obstáculo relevante, mas não insuperável, e não vejo quais poderiam ser os motivos para que os Estados decidam opor-se a tal modificação.

\section{UMA MELHOR ORGANIZAÇÃO DO TRABALHO}

Do ponto de vista do funcionamento da Corte, os problemas principais para os quais a Corte é chamada são, a meu ver, dois. Ambos requerem uma modificação ou uma adequação do procedimento e do método de trabalho da Corte.

O primeiro aspecto refere-se ao tempo de um processo diante da Corte. A Corte é um dos poucos tribunais internacionais que trabalha sempre em composição plenária e não em seções. Atualmente, a carga de trabalho permite respeitar sem muita dificuldade tal indicação. Se o número de causas aumentar de maneira considerável, uma organização mais eficiente em seções seria obrigatória. Ora, tal modificação seria possível somente através de uma modificação do Estatuto. Isso contempla, de fato, a possibilidade de atribuir a formações mais restritas - as câmaras. Todavia, com base no Estatuto, o recurso a uma câmara está sempre subordinado à existência de um acordo entre as partes em litígio. Hoje, a Corte está tentando tornar mais eficiente o seu trabalho impondo às partes tempos mais restritos para o procedimento oral e procurando limitar ao máximo o tamanho das memórias escritas. Outra solução poderia ser convidar sistematicamente as partes a utilizar as câmaras. Evidentemente, são pequenos corretivos; se a carga de trabalho aumentar de maneira consistente, eles podem revelar-se não mais suficientes.

O outro aspecto se refere à habilidade da Corte em resolver controvérsias que levantam difíceis questões técnico-científicas ou que impõem um atento e complexo exame dos fatos ${ }^{8}$. Como exemplo do primeiro tipo posso citar as controvérsias em matéria ambiental. Sobre esses nos debruçaremos mais amplamente amanhã. Como exemplo do outro tipo de controvérsias, pode-se pensar nos casos em que se verificam extensas de direitos humanos, como aquelas que se verificaram na Bósnia depois do desmembramento da ex-Iugoslávia. Quando a Corte é chamada para decidir questões técnico-científicas, ela precisa, evidentemente, da ajuda de especialistas. O Estatuto permite a nomeação de especialistas, mas a Corte é muito relutante em fazer uso deles. Nos últimos 50 anos, a Corte nomeou especialistas somente em 3 casos. Essa atitude da Corte 
deve necessariamente mudar. De outro modo, o risco é que as sentenças da Corte em matéria ambiental sejam percebidas como avaliações discricionárias por parte de juízes que não têm os instrumentos para avaliar os verdadeiros problemas trazidos pelo caso.

Quanto ao outro aspecto, a questão é ainda mais delicada. A Corte não parece preparada para decidir casos que impõem a oitiva de centenas de testemunhas, o envio de médicos legistas, etc. Diferentemente do que acontece diante de tribunais penais internacionais, o regulamento não diz nada sobre proteção de testemunhas, assunção de provas testemunhais em outras sedes e assim por diante. Atualmente, não são muitos os casos que apresentam esses tipos de situações. No caso relativo ao genocídio na Bósnia, a Corte foi muito beneficiada pelo fato de grande parte das provas já terem sido recolhidos pelo Tribunal penal internacional para a ex-Iugoslávia. Tais provas foram utilizadas pelas partes e referenciadas pela Corte na sua sentença de 2007. Resta o fato que a Corte deveria se perguntar sobre quais soluções adotar quando um novo caso desse tipo for submetido pelos Estados.

\section{CONCLUSÕES}

O sucesso atual da Corte não deve fazer perder de vista as dificuldades e os desafios futuros. Para ter condições de enfrentar tais desafios, creio que um passo importante seria iniciar uma discussão sobre as modificações do Estatuto. $\mathrm{O}$ atual Estatuto foi redigido em 1920. Em pouco tempo terá cem anos. Para muitas coisas, continua a funcionar perfeitamente. Para outras, mostra os sinais do tempo. $\mathrm{O}$ consenso manifestado pelos Estados em relação à Corte poderia ser utilizado para iniciar uma discussão, no nível dos Estados e no seio das Nações Unidas, para modificar algumas partes do Estatuto. Não creio que uma modificação de um instrumento técnico como o Estatuto possa levantar questões políticas relevantes, e, portanto, poderia ser realizada em um tempo razoável.

\section{NOTAS}

$1 \mathrm{O}$ art. $38, \S 1^{\circ}$, do Estatuto prevê que a Corte serve "to decide in accordance with international law such disputes as are submitted to it".

2 Com base no art. 65 do Estatuto, "the Court may give an advisory opinion on any legal question at the request of whatever body may be authorized by or in accordance with the Charter of the United Nations to make such a request".

3 Para um exame interessante das diversas épocas da Corte, Cf. Sir Robert Jennings e Dame Rosalyn Higgins (2012, p. 18 ss.).

4 Para um exame da atividade da Corte em ocasião do $50^{\circ}$ aniversário da sua criação, Cf. Luigi Condorelli, (1995, p. 388-400).

5 Entre os numerosos escritos que trabalham esse problema, Cf. Alain Pellet, (2004, p. 159 ss.), e Hugh Thirlway, (2010, p. 347 ss.). 
$6 \mathrm{O}$ art. $36, \S 2^{\circ}$, prevê que "the states parties to the present Statute may at any time declare that they recognize as compulsory ipso facto and without special agreement, in relation to any other state accepting the same obligation, the jurisdiction of the Court in all legal disputes (...)".

7 Sobre esse tema, Cf. Pierre-Marie Dupuy (2012, p. 585 ss.).

8 Cf. Markus Benzing (2012, p. 1234 ss.).

\section{Referências Bibliográficas}

BENZING, Markus. Evidentiry Issues. In: ZIMMERMANN, Andreas et al (Orgs.). The Statute of the International Court of Justice: a commentary. Oxford: Oxford University Press, 2012.

CONDORELLI, Luigi. La Cour internationale de justice: 50 ans et (pour l'heure) pas une ride. European Journal of International Law, p. 388-400, 1995.

DUPUY, Pierre-Marie. Article 34. In: ZIMMERMANN, Andreas et al (Orgs.). The Statute of the International Court of Justice: a commentary. Oxford: Oxford University Press, 2012.

JENNINGS, Sir Robert; HIGGINS, Dame Rosalyn. General Introduction. In:

ZIMMERMANN, Andreas et al (Orgs.). The Statute of the International Court of Justice: a commentary. Oxford: Oxford University Press, 2012.

PELLET, Alain. Strengthening the Role of the International Court of Justice as the principal judicial organ of United Nations. The Law and Practice of International Courts and Tribunals, 2004.

THIRLWAY, Hugh. The International Court of Justice 1989-2009: At the Heart of the Dispute Settlement System? Netherlands International Law Review, 2010. 


\section{Resumo}

Este artigo se propõe a realizar um rápido exame da história da Corte internacional de justiça, em particular do sucesso que ela teve perante os Estados como instrumento de solução de controvérsias, com o objetivo de compreender melhor quais são os desafios que a esperam em um futuro próximo. Entre tais desafios incluem-se, especificamente, o aumento da atratividade da Corte, alargando o acesso às organizações internacionais e a modificação de alguns aspectos processuais.

Palavras-chave: Corte internacional de justiça; solução de controvérsias internacionais; Nações Unidas. 


\title{
CHALLENGES AND PERSPECTIVES OF THE INTERNATIONAL COURT OF JUSTICE
}

\begin{abstract}
This article aims to make a fast exam of the history of the International Court of Justice, in particular the success that it had before the States as a conflict resolution instrument, with the objective of better understand what are the challenges that waits for it in a near future. Between its challenges are included, specifically, the increase of the Court attractiveness, extending the access to the international organizations and the modification of some procedure aspects.
\end{abstract}

Keywords: International Court of Justice. International conflicts resolution. United Nations. 


\section{Riassunto}

Lo scritto si propone di compiere un rapido esame della storia della Corte internazionale di giustizia, ed in particolare del successo da essa incontrato presso gli Stati come strumento di soluzione delle controversie, allo scopo di meglio comprendere quali sono le sfide che attendono la Corte nel prossimo futuro. Tra queste sfide rientrano in particolare quelle di accrescere l'attrattività della Corte, allargando l'accesso anche alle organizzazioni internazionali, e di modificare alcune aspetti della procedura.

Parole chiavi: Corte internazionale di giustizia; soluzione delle controversie internazionali; Nazioni Unite.

Recebido em 24 de agosto de 2017

Aprovado em 30 de maio de 2018 